\title{
A quinoline based pH sensitive ratiometric fluorescent sensor: Structure and spectroscopy
}

\author{
SOMA MUKHERJEE ${ }^{\mathrm{a}, *}$, AMIT KUMAR PAUL ${ }^{\mathrm{a}}$ and HELEN STOECKLI-EVANS ${ }^{\mathrm{b}}$ \\ ${ }^{a}$ Department of Environmental Science, University of Kalyani, Kalyani, Nadia 741 235, West Bengal, India \\ b Institute of Physics, University de Neuchatel, CH-2000 Neuchatel, Switzerland \\ e-mail: sommukh445@yahoo.co.in; somam580@gmail.com
}

MS received 2 April 2015; revised 23 June 2015; accepted 25 June 2015

\begin{abstract}
A new quinoline based hydrazone was synthesized via a condensation reaction and characterized by NMR, mass and single crystal X-ray diffraction studies. It was investigated for suitability as a reversible ratiometric fluorescent $\mathrm{pH}$ sensor in acidic $\mathrm{pH}$ region. The sensor exhibits intramolecular charge transfer (ICT) type photophysical changes upon protonation of the quinoline ring. No significant interference on emission behavior was observed in the presence of various metal ions.
\end{abstract}

Keywords. ICT; Ratiometric; Fluorescent pH sensor; Quinoline hydrazine; Structure.

\section{Introduction}

Analytic estimation of ion concentration through rationally designed molecular receptors is an active field of research. Various photophysical properties can be exploited for selective detection of an analyte. Fluorescence sensors are powerful tools for sensing biologically and environmentally important ions due to its superior selectivity, sensitivity and non-invasive approach. ${ }^{1-3}$ Among other fluorescence phenomenon that is being utilized for sensing purpose, intramolecular charge transfer (ICT) process has some distinctive advantages. ${ }^{4,5}$ It is generally accompanied by significant emission wavelength shift or Stokes shift upon interaction with the analyte permitting ratiometric estimation. $\mathrm{pH}$ is a vital parameter for biological systems ${ }^{6}$ as it controls enzymatic activity, cell proliferation, apoptosis, etc. Fluorescence $\mathrm{pH}$ sensors are emerging as crucial tools for visualizing noninvasive intracellular $\mathrm{pH}$ distribution. ${ }^{7-11}$ Besides this, fluorescent $\mathrm{pH}$ sensors are also applicable for imaging $\mathrm{pH}$ gradient in biofilms ${ }^{12}$ providing important information about its microenvironment. In this work, we have synthesized and characterized a quinoline based fluorescent probe $^{13-16}$ as a new ratiometric fluorescent $\mathrm{pH}$ sensor. The sensor displayed high sensitivity over the acidic $\mathrm{pH}$ range (3.5-5.5) and no significant interference was observed in the presence of various metal ions.

\footnotetext{
*For correspondence
}

\section{Experimental}

\subsection{Materials and general methods}

All analytic grade reagents were purchased commercially. FTIR data were collected with the help of Spectrum One FT-IR Spectrometer. NMR spectra were recorded on a Bruker DRX-400 spectrometer with TMS as the internal standard in DMSO- $\mathrm{d}_{6}$. Absorption spectra were measured on a Shimadzu UV-1700 spectrophotometer. Fluorescence measurements were performed on a Hitachi F7000 spectrofluorimeter. Mass spectra measurement was carried out by Waters Xevo G2$\mathrm{S}$ QTof Mass Spectrometer. $\mathrm{pH}$ measurements were carried out using Orion 3-Star Plus pH Benchtop Meter.

\subsection{Synthesis}

The compound $\mathbf{1}$ was synthesized by stirring an equimolar amount of quinoline-2-aldehyde $(0.2 \mathrm{~m} \mathrm{M}$, $0.031 \mathrm{~g})$ and $p$-tolyl hydrazine $(0.2 \mathrm{mM}, 0.024 \mathrm{~g})$ in methanol-dichloromethane $(1: 1 \mathrm{v} / \mathrm{v})$ at room temperature for $30 \mathrm{~min}$. The desired product was obtained in good yield by slow evaporation of this solution. ${ }^{8,17}$ The deprotonated form of $\mathbf{1}$ was prepared by adding few drops of methanolic $1 \mathrm{~N} \mathrm{KOH}$ to the solution of $\mathbf{1}$ (scheme 1).

1: Yield: $0.044 \mathrm{~g}$ (82\%). $\mathrm{C}_{17} \mathrm{H}_{15} \mathrm{~N}_{3},{ }^{1} \mathrm{H}$ NMR 10.9 $(1, \mathrm{~s}), 8.29(1, \mathrm{~s}), 8.13-8.11(1, \mathrm{~d}), 8.00-7.95(3, \mathrm{~m}), 7.93$ $(1, \mathrm{t}), 7.73(1, \mathrm{~s}), 7.57-7.55(1, \mathrm{~m}), 7.10(4, \mathrm{~s}), 2.24$ $(3, \mathrm{~s}) ; \mathrm{m} / \mathrm{z}(\mathrm{ESI})[\mathrm{M}+\mathrm{H}]^{+}$262.1(calculated 262.3). FTIR $\left(\mathrm{KBr}\right.$ pellet, $\left.\mathrm{cm}^{-1}\right)$ : 3384, 2915, 1639, 1601, 1547, 


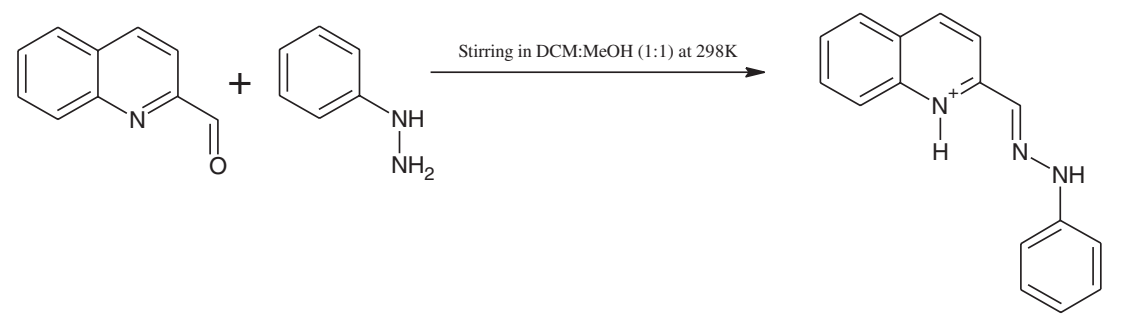

Scheme 1. Synthesis.

$1499,1410,1385,1346,1295,1268,1234,1195,1148$, 1123, 1060, 768, 616.

\section{$2.3 X$-ray crystallography}

The compound $\mathbf{1}$ was crystallized in the protonated form by slow evaporation of a methanolic solution. The intensity data were collected at $173 \mathrm{~K}$ on a Stoe Mark II-Image Plate Diffraction System ${ }^{18}$ equipped with a two-circle goniometer and using $\mathrm{MoK} \alpha$ graphite monochromated radiation $(\lambda=0.71073 \AA)$. The structure was solved by direct methods with SHELXS-97. ${ }^{19}$ The refinement and all further calculations were carried out with SHELXL-97. ${ }^{19}$ The $\mathrm{NH}$ and water H-atoms were located in difference Fourier maps and freely refined. The C-bound $\mathrm{H}$-atoms were included in calculated positions and treated as riding atoms: $\mathrm{C}-\mathrm{H}=$ $0.95-0.98 \AA$ with $\mathrm{U}_{\text {iso }}(\mathrm{H})=1.5 \mathrm{U}_{\text {eq }}$ (parent $\mathrm{C}$-atom) for methyl $\mathrm{H}$ atoms and 1.2 $\mathrm{U}_{\text {eq }}$ (parent $\mathrm{C}$-atom) for other $\mathrm{H}$ atoms. The non- $\mathrm{H}$ atoms were refined anisotropically, using weighted full-matrix least-squares on $F^{2}$. A semi-empirical (multi-scan) absorption correction was applied using the MULABS routine in PLATON. ${ }^{20}$ The molecular structure with the crystallographic numbering scheme, together with the crystal packing are illustrated in figures $1-3$, drawn using the program Mercury. ${ }^{21}$ Further crystallographic data and refinement details are given in table 1.

\subsection{Sample preparation for UV-Vis and fluorescence measurements}

A stock solution of $\mathbf{1}(0.5 \mathrm{mM})$ was prepared in $\mathrm{MeOH}$. The solutions for spectroscopic measurements were obtained by diluting the stock solutions to $5 \mathrm{~mL}(1 \times$ $10^{-5} \mathrm{M}$ ) by deionized water. In the titration experiment, $3 \mathrm{~mL}$ solution of $\mathbf{1}\left(1 \times 10^{-5} \mathrm{M}\right)$ was poured into a quartz optical cell of $1 \mathrm{~cm}$ path length each time and slight $\mathrm{pH}$ variations of the solution were achieved by adding minimum volume of $\mathrm{NaOH}$ or $\mathrm{HCl}$. The $\mathrm{pH}$ of the solution was measured for each measurement. The fluorescence titration experiment was investigated in a similar procedure with $\left(5 \times 10^{-5} \mathrm{M}\right)$ solution and the excitation wavelength was $310 \mathrm{~nm}$. Quantum yields (Q) were calculated in aqueous medium $\left(\mathrm{CH}_{3} \mathrm{CN} / \mathrm{H}_{2} \mathrm{O}(1: 4\right.$, $\mathrm{v} / \mathrm{v})$ solvent system) by secondary method with respect to the quinine sulfate $\left(\Phi=0.55\right.$ in $\left.0.1 \mathrm{M} \mathrm{H}_{2} \mathrm{SO}_{4}\right)$ as standard, ${ }^{22}$ using eq. (1):

$$
\mathrm{Q}=\mathrm{Q}_{\mathrm{R}} \times\left(\mathrm{I} / \mathrm{I}_{\mathrm{R}}\right) \times\left(\mathrm{OD}_{\mathrm{R}} / \mathrm{OD}\right) \times \eta^{2} / \eta_{\mathrm{R}}^{2}
$$

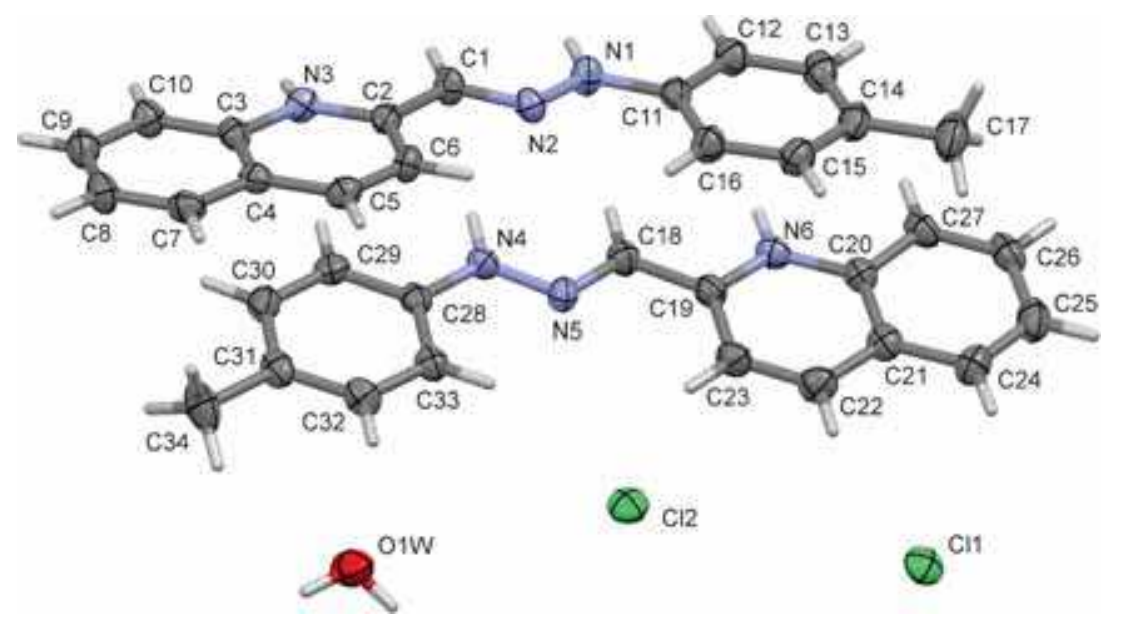

Figure 1. A view of the molecular structure of compound $\mathbf{1}$ with atom labelling. Displacement ellipsoids are drawn at the $50 \%$ probability level. 


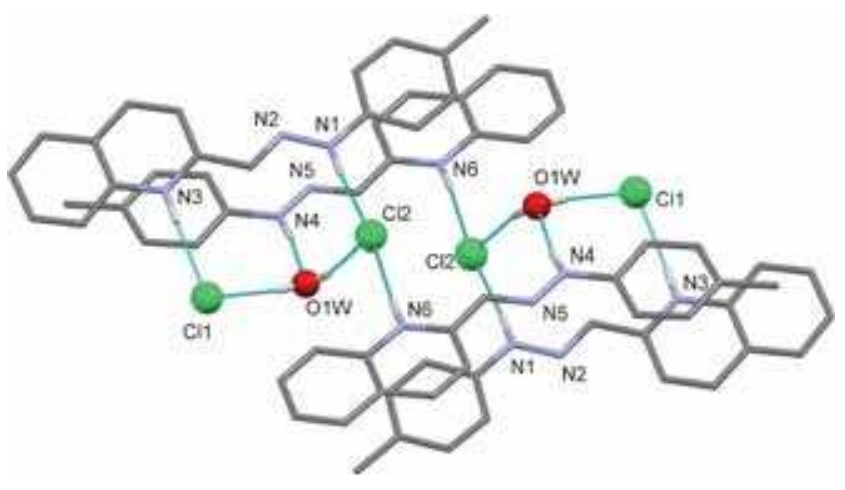

Figure 2. A view of the hydrogen bonded tetramer-like unit, possessing inversion symmetry. Hydrogen bonds are shown as sky blue colored dotted line.

where, Q is the quantum yield, I is the integrated area corresponding to the fluorescence spectrum, OD is the optical density, and $\eta$ is the refractive index. The subscript $\mathrm{R}$ refers to the reference fluorophore of known quantum yield.

To determine the fluorescence response of $\mathbf{1}$ to different metal cations, the stock solution of $\mathbf{1}$ was diluted to $1 \times 10^{-5} \mathrm{M}$ with phosphoric acid buffer $(\mathrm{pH} 7.4)$ and acetic acid- sodium acetate buffer $(\mathrm{pH}$ 4.0) for interference study at the working $\mathrm{pH}$ range. The interference was measured by adding metal salt solutions and measuring the emission after complete mixing.

\section{Results and Discussion}

\subsection{Synthesis}

The compound $\mathbf{1}$ was synthesized following a general procedure. ${ }^{8,17}$ It was characterized by ${ }^{1} \mathrm{H}$ NMR, mass and single crystal X-ray diffraction studies (scheme 2).

\subsection{Single crystal $X$-ray diffraction studies}

The molecular structure of compound $\mathbf{1}$ was confirmed by single crystal X-ray diffraction studies. It crystallized in the protonated form with two independent cations (A involving atoms N1-N3, and B involving atoms N4-N6, two $\mathrm{Cl}^{-}$anions and a water molecule of crystallization in the asymmetric unit (figure 1). Both cations (A and B) are essentially planar with the benzene ring being inclined to the mean plane of the protonated quinoline moiety by $6.46(14)^{\circ}$ in cation $\mathrm{A}$ and $3.24(14)^{\circ}$ in cation B. The bridging C11-N1-N2-C1 and C28-N4-N5-C18 torsion angles are -179.6(3) and $-178.0(3)^{\circ}$, respectively.

In the crystal of $\mathbf{1}$, the cations, anions and the water molecule and linked by N-H...O, N-H. . Cl and O$\mathrm{H}$... Cl hydrogen bonds (table S1 in Supplementary Information) forming a tetramer-like unit possessing inversion symmetry (figure 2). These units in turn are linked by $\mathrm{C}-\mathrm{H}$. . . Cl and $\mathrm{C}-\mathrm{H}$. . .O hydrogen bonds and

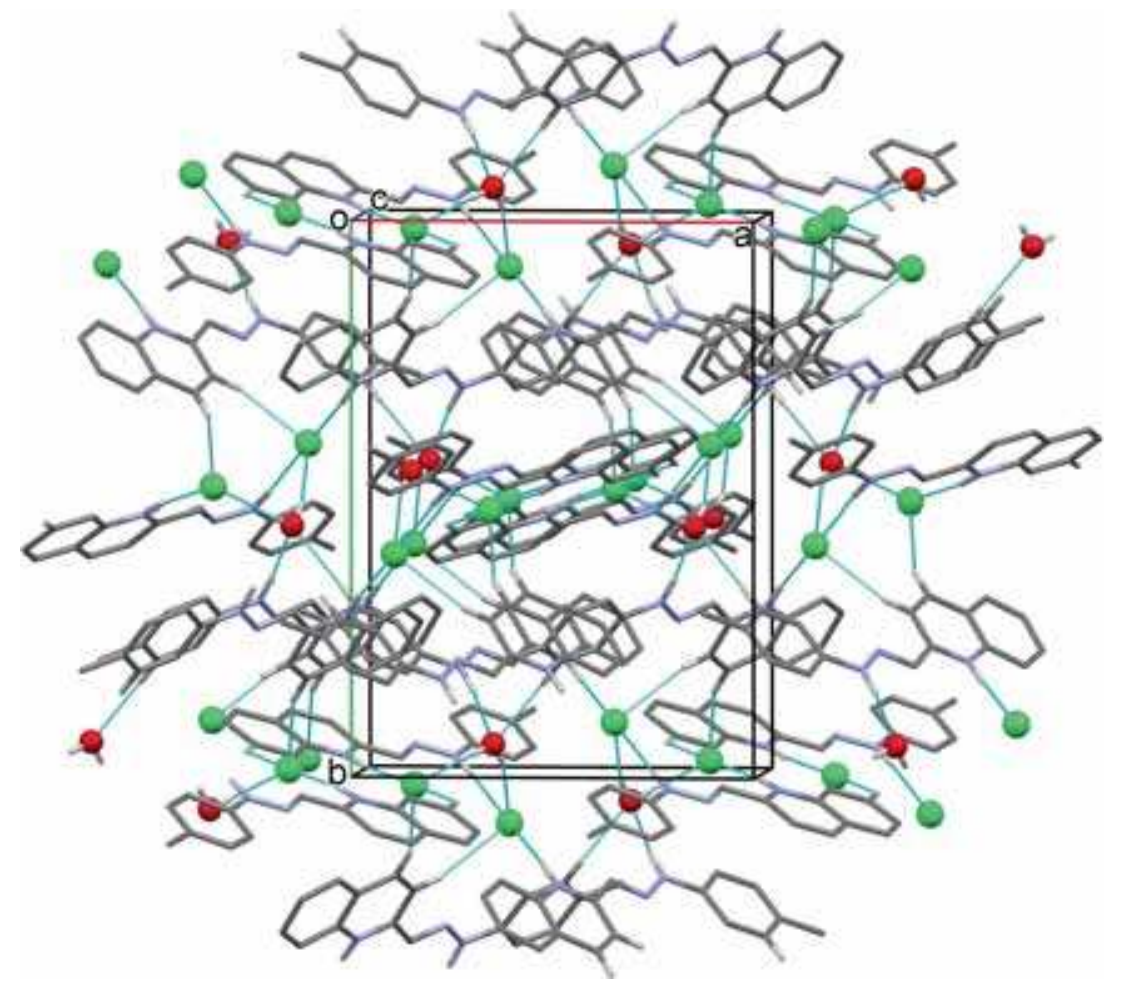

Figure 3. A view along the $c$ axis of the crystal packing of compound 1. Hydrogen bonds are shown as dashed lines. 
Table 1. Crystallographic data and structure refinement parameters for $\mathbf{1}$.

\begin{tabular}{|c|c|}
\hline & 1 \\
\hline Formula & {$\left[\mathrm{C}_{17} \mathrm{H}_{16} \mathrm{~N}_{3}\right]^{+\cdot} \mathrm{Cl}^{-\cdot} 0.5\left(\mathrm{H}_{2} \mathrm{O}\right)$} \\
\hline $\mathrm{M}_{\mathrm{r}}\left(\mathrm{g} \mathrm{mol}^{-1}\right)$ & 306.79 \\
\hline Cryst. dimension (mm) & $0.45,0.35,0.19$ \\
\hline Space group & $\mathrm{P} 22_{1} / \mathrm{a}$ \\
\hline$T(\mathrm{~K})$ & $173(2)$ \\
\hline$a(\AA)$ & $13.007(1)$ \\
\hline$b(\AA)$ & $17.3207(9)$ \\
\hline$c(\AA)$ & $14.7900(11)$ \\
\hline$\alpha\left(^{\circ}\right)$ & 90.00 \\
\hline$\beta\left({ }^{\circ}\right)$ & $103.129(6)$ \\
\hline$\gamma\left({ }^{\circ}\right)$ & 90.00 \\
\hline$V\left(\AA^{3}\right)$ & $3244.9(4)$ \\
\hline$Z$ & 8 \\
\hline$D_{\text {calc }}\left(\mathrm{g} / \mathrm{cm}^{3}\right)$ & 1.256 \\
\hline$\mu\left(\mathrm{mm}^{-1}\right)$ & 0.236 \\
\hline$F(000)$ & 1288 \\
\hline$\theta$ Range $\left(^{\circ}\right)$ & $1.41-25.69$ \\
\hline Reflections measured & 24754 \\
\hline Reflections unique & 6115 \\
\hline $\mathrm{R}$ (int) & 0.127 \\
\hline Reflections observed $[I>2 s(I)]$ & 3478 \\
\hline Data/parameters & $6115 / 408$ \\
\hline$G O F$ & 1.005 \\
\hline${ }^{\mathrm{a}} R_{1}, w R_{2}^{\mathrm{b}}[I>2 \sigma(I)]$ & $0.0739,0.1017$ \\
\hline${ }^{\mathrm{b}} R_{1}, w R_{2}^{\mathrm{b}}$ (all data) & $0.1402,0.1171$ \\
\hline Largest diff peak and hole $\left[\mathrm{e}^{-3}\right]$ & $0.198,-0.237$ \\
\hline
\end{tabular}

${ }^{\mathrm{a}} R_{1}=\left[\Sigma|| F_{\mathrm{o}}-\left|F_{\mathrm{c}}\right| \mid\right] / \Sigma\left|F_{\mathrm{o}}\right|($ based on $F)$

${ }^{\mathrm{b}} w R_{2}=\left[\left[\Sigma w\left(\left|F_{\mathrm{o}}{ }^{2}-F_{\mathrm{c}}{ }^{2}\right|\right)^{2}\right] /\left[\Sigma w\left(F_{\mathrm{o}}{ }^{2}\right)^{2}\right]\right]^{1 / 2}\left(\right.$ based on $\left.F^{2}\right)$<smiles>Cc1ccc(N/N=C/c2ccc3ccccc3[nH+]2)cc1</smiles>

1<smiles>Cc1ccc(N/N=C/c2ccc3ccccc3n2)cc1</smiles>

Deprotonated 1

Scheme 2. Protonated and deprotonated forms of $\mathbf{1}$.

C-H. . $\pi$ (table S1) and $\pi-\pi$ interactions [centroidto-centroid distances vary from 3.684(2) to 3.784(2) ̊] forming a three-dimensional framework structure (figure 3).

\subsection{Spectroscopic responses to $\mathrm{pH}$}

In aqueous medium (1\% methanol, $\mathrm{pH} 7.0)$ the compound 1 exhibits a strong absorption band at $374 \mathrm{~nm}$ which gradually decreases with decreasing $\mathrm{pH}$ up to 2.0 followed by the generation of a new peak centered at $455 \mathrm{~nm}$ (figure 4). Further decrease in $\mathrm{pH}$ does not induce any change in the spectrum. Increasing $\mathrm{pH}$ of the same solution exhibits similar spectral pattern indicating that the changes are completely reversible. This spectral change was also detected optically as the color of the solution changes from red to faint yellow as the $\mathrm{pH}$ of the medium increases. 


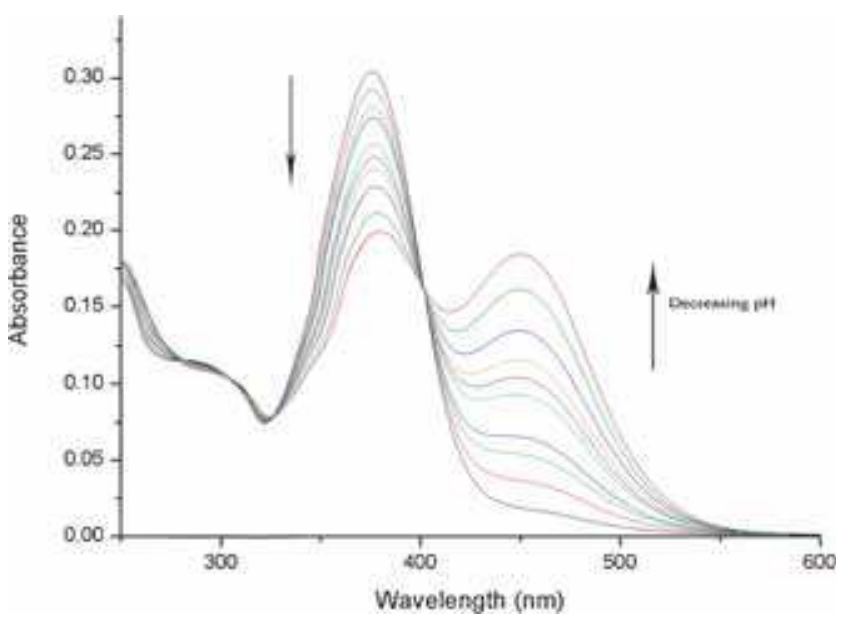

Figure 4. Absorption spectra of $1\left(1.0 \times 10^{-5} \mathrm{M}\right)$ in aqueous solution (1\% methanol) at different $\mathrm{pH}(7.0,6.5,6.0$, $5.75,5.25,4.75,4.25,3.75,3.25,2.75)$.

In aqueous solution $(\mathrm{pH}=7.0,1 \%$ methanol) 1 emits at $455 \mathrm{~nm}$ ( $\lambda_{\mathrm{ex}}=310 \mathrm{~nm}$, an isosbestic point) with a large Stokes shift of $81 \mathrm{~nm}$. With the gradual decrease of $\mathrm{pH}$ from 7.0 to 2.75 the emission band undergoes a significant red shift to $507 \mathrm{~nm}$. The $\mathrm{pK}_{\mathrm{a}}$ values of $\mathbf{1}$ were found to be 4.84 (absorbance) and 4.76 (fluorescence), respectively, as calculated from Henderson - Hasselbalch equation, $\left(\mathrm{pH}=\mathrm{pK}_{\mathrm{a}}+\log ([\mathrm{salt}] /[\mathrm{acid}])\right)$ (figures 5 and 6). This photophysical change due to the lowering of $\mathrm{pH}$ of the medium can be attributed to the protonation of the quinoline ring which in turn promotes stronger charge transfer from the benzene ring. ${ }^{8,23}$ To get an insight into the solvatochromic behavior of the protonated and deprotonated forms, the spectral dependency of $\mathbf{1}$ on solvent polarity was examined. It was found that both the absorption and emission spectra of $\mathbf{1}$ and deprotonated $\mathbf{1}$ show bathochromic shifts with increasing solvent polarity (table 2) which might be due

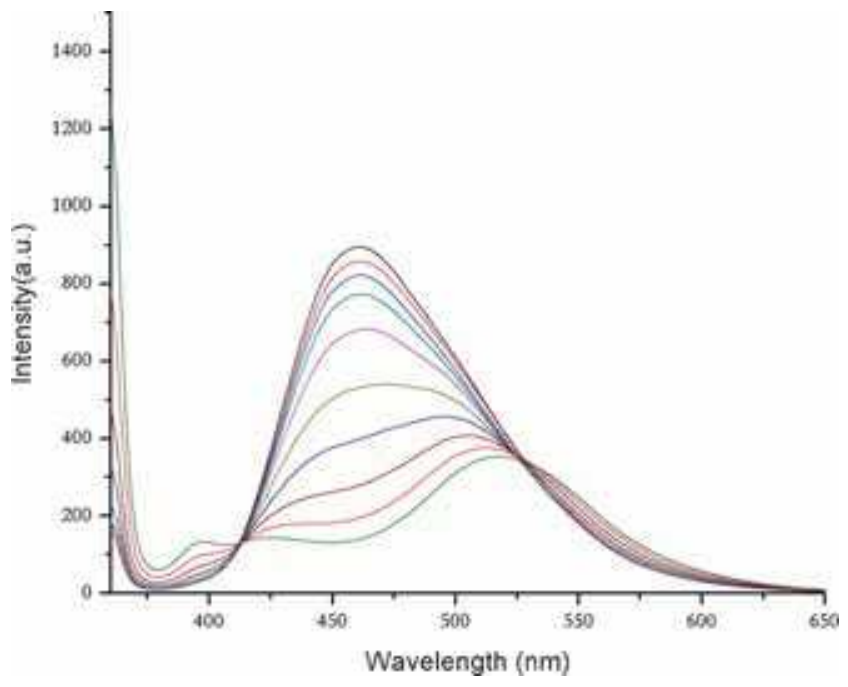

Figure 6. Emission spectra of $\mathbf{1}\left(5.0 \times 10^{-5} \mathrm{M}\right)$ at different $\mathrm{pH}(7.0,6.5,6.0,5.75,5.25,4.75,4.25,3.75,3.25,2.75)$. $\lambda_{\mathrm{ex}}=310 \mathrm{~nm}$.

the internal charge transfer. A plot of intensity ratio, $\mathrm{I}_{455} / \mathrm{I}_{507}$ against $\mathrm{pH}$ for $\mathbf{1}$ is shown in figure 7 . The quantum yield for the compound $\mathbf{1}$ in $\mathrm{pH} 7$ was determined as 0.009 . The reversible nature and reproducibility of the sensor was tested by recording the ratio of fluorescence intensity at $507 \mathrm{~nm}$ and $445 \mathrm{~nm}$ with the change of $\mathrm{pH}$ in 4 to 7 range, and vice versa, up to 6 cycles (figure 8). Thus, the sensor might be applicable for real time $\mathrm{pH}$ monitoring.

To establish its applicability in biological systems where different metal ions are present in cellular or extracellular environment, selectivity of $\mathbf{1}$ towards different metal ions such as $\mathrm{Na}^{+}, \mathrm{K}^{+}, \mathrm{Ca}^{2+}, \mathrm{Mg}^{2+}, \mathrm{Cu}^{2+}$, $\mathrm{Ni}^{2+}, \mathrm{Mn}^{2+}, \mathrm{Fe}^{2+}, \mathrm{Zn}^{2+}$ and $\mathrm{Fe}^{3+}$ in aqueous solution (1\% methanol) emission spectra were recorded at $\mathrm{pH} 7.4$ and 4.0. No obvious change in the emission
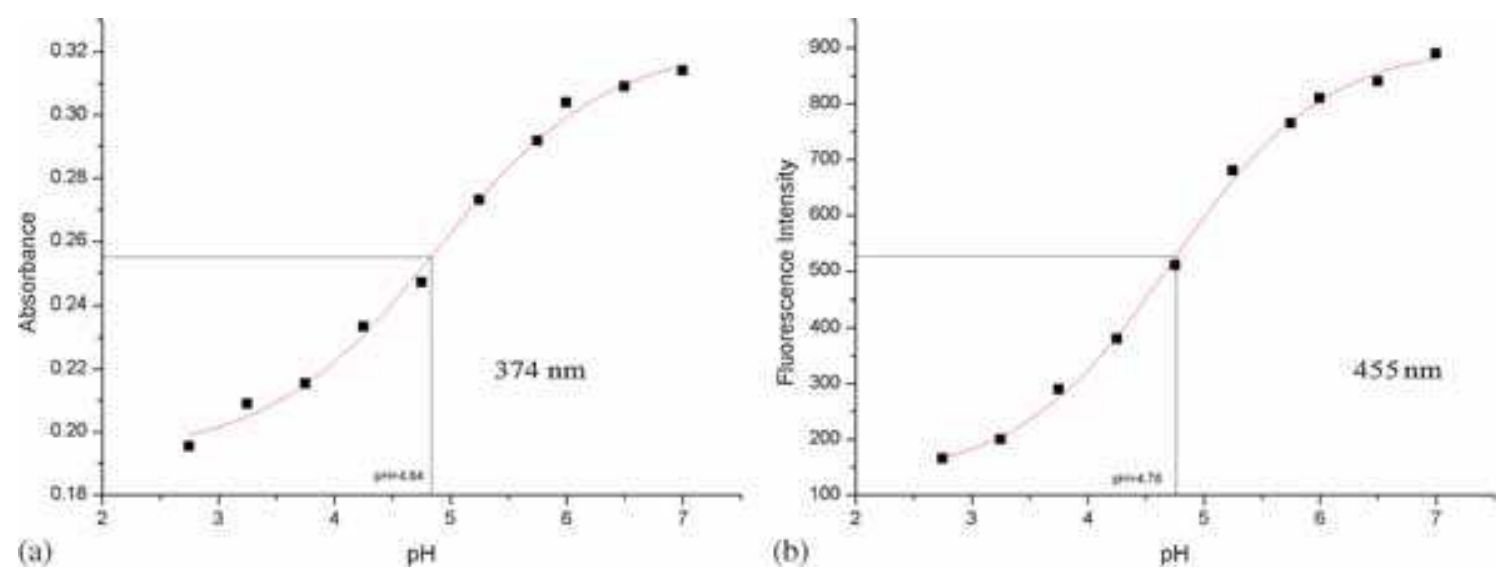

Figure 5. (a) Plot of absorbance of $\mathbf{1}$ at $374 \mathrm{~nm}$ and; (b) Plot of fluorescence intensity at $455 \mathrm{~nm}$ as a function of pH. 
Table 2. Solvent dependent absorption and emission maxima (in $\mathrm{nm}$ ) of $\mathbf{1}$.

\begin{tabular}{lrrrr}
\hline & \multicolumn{2}{c}{ deprotonated 1 } & \multicolumn{2}{c}{ 1 } \\
\hline Solvent & $\lambda_{\text {abs }}$ & $\lambda_{\text {ff }}$ & $\lambda_{\text {abs }}$ & $\lambda_{\text {fl }}$ \\
DMSO & 378 & 445 & 448 & 501 \\
MEOH & 376 & 442 & 442 & 495 \\
DCM & 374 & 435 & 441 & 482 \\
$\mathrm{CHCl}_{3}$ & 370 & 431 & 437 & 480 \\
\hline
\end{tabular}

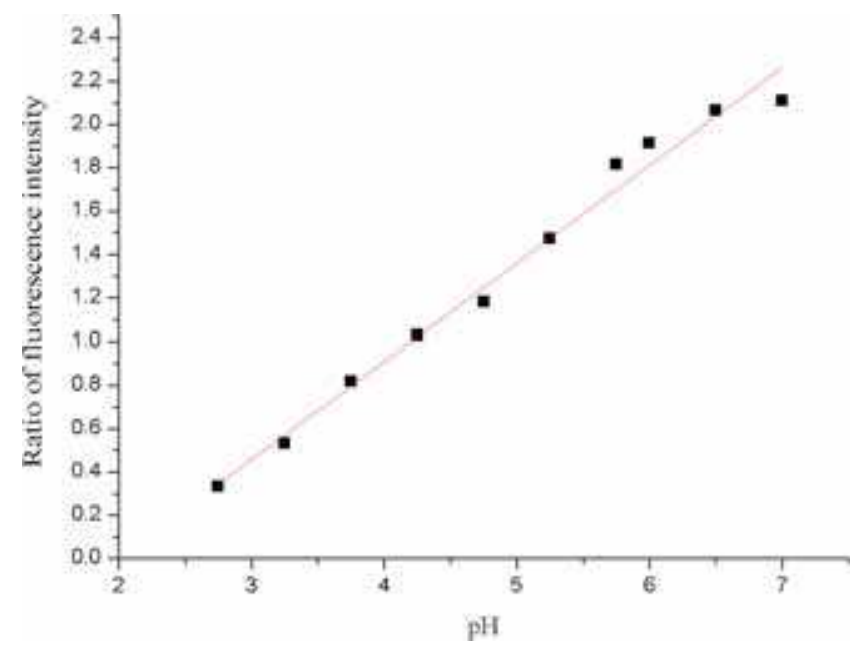

Figure 7. Ratiometric curve of $\mathrm{I}_{455} / \mathrm{I}_{507}$ as a function of $\mathrm{pH}$.

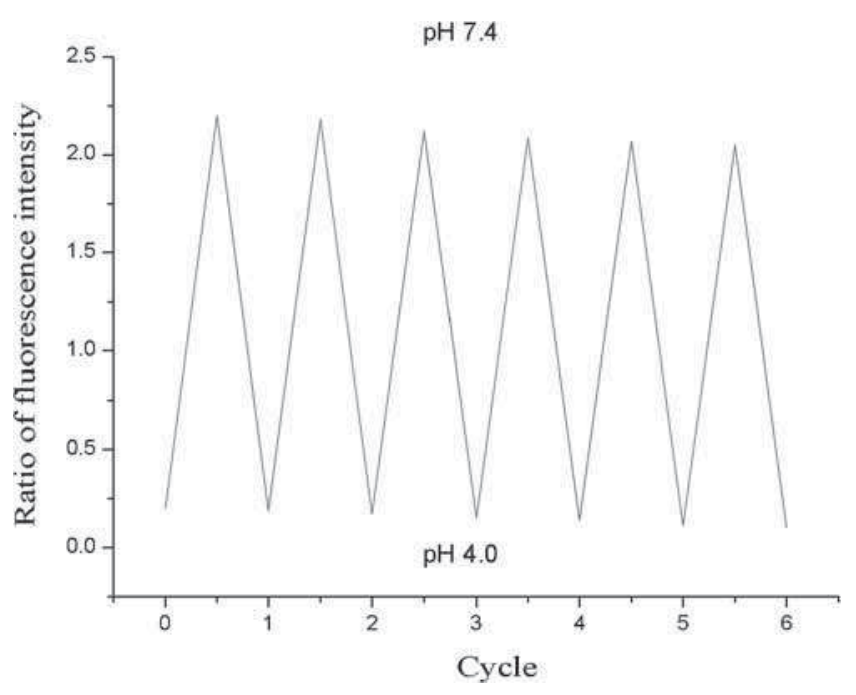

Figure 8. The ratio of fluorescence intensity at $455 \mathrm{~nm}$ and $507 \mathrm{~nm}$ of $1\left(\lambda\right.$ ex $=310 \mathrm{~nm}, 5.0 \times 10^{-5} \mathrm{M}$ in $1 \%$ aqueous methanol) upon consecutive addition of $1(\mathrm{~N}) \mathrm{HCl}$ and $1(\mathrm{~N})$ $\mathrm{NaOH}$ solution up to 6 cycles.

ratio was observed, even though manifold equivalents of metal ions were added to 1 (figure 9).

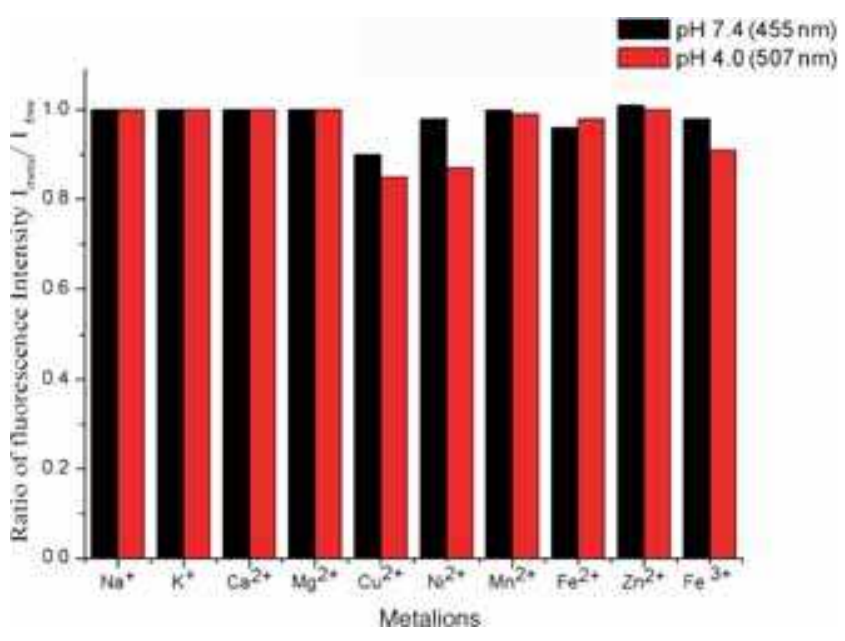

Figure 9. Ratio of fluorescence intensity of $\mathbf{1}(5.0 \times$ $\left.10^{-5} \mathrm{M}, \lambda_{\mathrm{ex}}=310 \mathrm{~nm}\right)$ at $455 \mathrm{~nm}(\mathrm{pH} 7.4)$ and $507 \mathrm{~nm}(\mathrm{pH}$ 4.0) in aqueous solution (1\% methanol) in the presence of various metal ions, at ratio 10:1 (other ions: 1) for $\mathrm{Cu}^{2+}$, $\mathrm{Ni}^{2+}, \mathrm{Mn}^{2+}, \mathrm{Fe}^{2+}, \mathrm{Zn}^{2+}$ and $\mathrm{Fe}^{3+}$, while for $\mathrm{Na}^{+}, \mathrm{K}^{+}, \mathrm{Ca}^{2+}$ and $\mathrm{Mg}^{2+}$, the ratio is $10^{5}: 1$.

\section{Conclusion}

In summary, we have synthesized and characterized an ICT based ratiometric fluorescent $\mathrm{pH}$ sensor with large Stokes shift through condensation of quinoline aldehyde and $p$-tolyl hydrazine. The molecular structure of this hydrazone was determined by single crystal Xray diffraction studies. The sensor exhibits reversible absorption and emission change in the acidic region and the consequent photophysical change can easily be detected by naked eye and ratiometric measurements.

\section{Supplementary Information}

CCDC 1055117 contains the supplementary crystallographic data for compound $\mathbf{1}$. These data can be obtained free of charge via http://www.ccdc.cam.ac. uk/conts/retrieving.html, or from the Cambridge Crystallographic Data Centre, 12 Union Road, Cambridge CB2 1EZ, UK; fax: (+44) 1223-336-033; or e-mail: deposit@ccdc.cam.ac.uk. Details of the hydrogen bond 
geometry (table S1) are available at www.ias.ac.in/ chemsci.

\section{Acknowledgements}

Financial support received from DST-FIST and DSTPURSE, New Delhi and the Indo-Swiss Joint Research Programme (ISJRP) for Joint Utilization of Advanced Facilities (JUAF) are gratefully acknowledged. We are thankful to the University of Kalyani for providing infrastructural facilities.

\section{References}

1. Yang Y, Zhao Q, Feng W and Li F 2013 Chem. Rev. 113 192

2. Schäferling M 2012 Angew. Chem. Int. Ed. 513532

3. Wu J, Liu W, Ge J, Zhang H and Wang P 2011 Chem. Soc. Rev. 403483

4. Yu F, Li P, Song P, Wang B, Zhao J and Han K 2012 Chem. Commun. 482852

5. Mei Y and Bentley P A 2006 Bioorg. Med. Chem. Lett. 163131

6. Roos A and Boron W F 1981 Physiol. Rev. 61296

7. Wang R, Yu C, Yu F, Chen L and Yu C $2010 \operatorname{Tr} A C$ Trends Anal. Chem. 291004

8. Mukherjee S, Paul A K, Rajak K K and Stoeckli-Evans H 2014 Sens. Actuators B: Chem. 203150
9. Han J and Burgess K 2010 Chem. Rev. 1102709

10. Briggs M S, Burns D D, Cooper M E and Gregory S J 2000 Chem. Commun. 2323

11. Saha U C, Dhara K, Chattopadhyay B, Mandal S K, Mondal S, Sen S, Mukherjee M, Smaalen S V and Chattopadhyay P 2011 Org. Lett. 134510

12. Schlafer S, Garcia J E, Greve M, Raarup M K, Nyvad B and Dige I 2015 Appl. Environ. Microbiol. 811267

13. Kalogianni A, Pefkianakis E, Stefopoulos A, Bokias G and Kallitsis J K 2010 J. Polym. Sci. Polym. Phys. 48 2078

14. Moutsiopoulou A, Andreopoulou A K, Lainioti G, Bokias G, Voyiatzis G and Kallitsis J K 2015 Sens. Actuators B: Chem. 211235

15. Zhu S, Lin W and Yuan L 2013 Dyes Pigm. 99465

16. Phukan S, Saha M, Pal A K and Mitra S 2013 J. Mol. Struct. 1039119

17. Mukherjee S, Paul A K and Stoeckli-Evans H 2014 Sens. Actuators B: Chem. 2021190

18. Stoe \& Cie 2009 X-Area \& X-RED32. Stoe \& Cie $\mathrm{GmbH}$, Darmstadt, Germany

19. Sheldrick G M 2008 Acta Cryst. A 64112

20. Spek A L 2009 Acta Cryst. D 65148

21. Macrae C F, Bruno I J, Chisholm J A, Edgington P R, McCabe P, Pidcock E, Rodriguez-Monge L, Taylor R, van de Streek J and Wood P A 2008 J. App. Cryst. 41 466

22. Fletcher A N 1969 Photochem. Photobiol. 9439

23. Niu W, Fan L, Nan M, Li Z, Lu D, Wong M S, Shuang S and Dong C 2015 Anal. Chem. 872788 